\title{
Perceived impacts of artificial intelligence and responses to positive behaviour change intervention"
}

\author{
Iis Tussyadiah and Graham Miller \\ School of Hospitality and Tourism Management \\ University of Surrey, United Kingdom \\ \{i.tussyadiah; g.miller\}@ surrey.ac.uk
}

\begin{abstract}
Artificial intelligence (AI) technologies have a great potential to aid not only in promoting tourism products and services, but also in influencing responsible travel behaviour to support sustainability. The effectiveness of using AI for positive behaviour change interventions depends on consumers' attitudes toward AI. This study found three underlying views of AI impacts: Beneficial AI, Destructive AI, and Risky AI. Based on these, three consumer segments were identified: The Laggards, The Aficionados, and The Realists. The first two segments hold opposing views: the former averaging higher in negative impacts, while the latter in positive impacts of AI. The Realists are aware of both benefits and risks of AI. These segments differ in their intention to follow recommendations from AI. It is suggested that mainstream consumers, those belonging to The Realists, are likely to respond positively to AI systems recommending responsible behaviour, signifying the positive role of $\mathrm{AI}$ in sustainable tourism.
\end{abstract}

Keywords: artificial intelligence; segmentation; profiling; positive behaviour change; sustainable tourism.

\section{AI and its Potentials}

Consumers increasingly use artificial intelligence (AI) technologies for everyday activities, whether they realise it or not $[1,2,3]$. With the prevalent use of smartphones, digital personal assistants powered by natural language processing (NLP) and speech recognition program, such as Apple's Siri and Google's Allo, gradually become the apps of choice when it comes to searching for information and personalised recommendations for products and services [1]. In travel and tourism, using a combination of NLP and machine learning, chatbots (typically integrated into popular messaging apps such as WhatsApp and Facebook Messenger) and robot concierges are readily available to assist tourists in making decision on flights, hotels, tour packages, attractions, etc. From the industry perspective, the advancement in AI capabilities translates into business advantages as AI systems could assist in streamlining business processes, increasing productivity, and providing better customer experience [2, 4]. As a result, the pace of adoption of AI by companies is accelerating, with $75 \%$ executives surveyed in 2016 revealing the plan to actively implement AI within the three-year planning horizon [5]. As some of future AI implementations will be consumer-facing, the advancement and business adoption of $\mathrm{AI}$ in various industries will, in turn, provide more opportunities for consumers to enjoy the benefits offered by sophisticated service tools.

\footnotetext{
* Citation: Tussyadiah, I., \& Miller, G. (2019). Perceived impacts of artificial intelligence and responses to positive behaviour change intervention. In Pesonen, J., \& Neidhardt, J. (Eds.), Information and Communication Technologies in Tourism 2019. Springer.
} 
Importantly, the promise of improvements in AI performance is not limited to its economic value, but also its societal benefits. Indeed, AI researchers have advocated the importance of efforts to recognise and optimise the positive impacts of AI in society beyond economic interests, while avoiding its potential pitfalls [6]. For example, AI has been touted to have the potentials to expand opportunities and access to education and vital services (legal, medical, transportation, etc.) for disadvantaged communities [4], and, due to its social and proactive features that could lead to trust and reliance [7], play a role in influencing positive behaviour change [8, 9]. In tourism context, intelligent systems can be designed to influence consumer choices, not only from a marketing point of view, but also from a social perspective, such as promoting socially desirable choices to tourists [10]. Hence, in order to support sustainable tourism development, chatbots and companion robots can be designed as persuasive agents in behaviour modification and intervention efforts involving travel consumers (e.g., promotion of responsible travel behaviour).

The success of such behaviour intervention depends highly on consumers' intention to rely on AI systems for recommendations. To that end, tourism researchers found a paradox in tourist behavioural responses to intelligent agents [11]. While perceived proactivity, intelligence and social ability of agents lead to trust, perceived reactivity and control often result in anxiety and, eventually, lessen consumers' intention to rely on intelligent agents for recommendations while travelling [11]. Hence, understanding consumers' perception of AI is important in anticipating the effectiveness of implementing AI for behaviour modification.

Public discourse about the future of AI holds two opposing visions: optimistic (e.g., AI will spur innovation and provide greater conveniences) and pessimistic (e.g., AI will raise issues of surveillance and displace workers) ones [3, 12]. By analysing public engagement and impressions expressed about AI over time in various media, a study found that although discussions around AI have grown more optimistic in recent years, specific concerns regarding AI, such as fear of loss of control of AI, have persisted and even increased recently [12]. More specifically, based on a study with consumers and business decision makers in the US [5], it was found that the majority of consumers are more optimistic about AI, in that they believe AI could solve complex problem in society $(63 \%)$ and help people live more fulfilling lives (59\%). However, some concerns regarding AI harming people by taking away jobs (46\%), and having serious, negative implications $(23 \%)$ were also identified. Most of those who hold negative sentiments toward AI have not used AI technologies before [2]. These findings imply that there are distinct groups of consumers holding opposing views of AI in society and that these groups will respond differently to AI systems designed to influence positive behavioural change.

In order to tap into the potentials of using AI systems to facilitate more responsible tourism, understanding consumers in terms of their perception of AI will be a necessary first step in developing positive behaviour change intervention strategies targeting travel consumers. While researchers have started to assess awareness of and attitude toward AI systems and predict their behavioural outcomes [13, 14], there is limited effort to explore meaningful, recognisable characteristics that differentiate consumers in terms of their perception of AI. Therefore, the aim of this research is to identify consumers' perception regarding what AI will bring to society and how this perception 
plays a role in better understanding their behaviour. Specifically, the research objectives are threefold: (1) to identify the underlying dimension(s) of perceived impacts of AI, (2) to segment and profile consumers based on their perceived impacts of AI, and (3) to explore whether perceived impacts of AI explain consumer behaviour with AI systems. The findings will inform travel and tourism destinations, hospitality companies, and government agencies with appropriate consumer typologies for effective targeting in implementation of positive behavioural change intervention utilising AI systems

\section{Attitudinal Segmentation in AI Adoption}

The advancement in AI capabilities presents a great potential for tourism destinations and hospitality companies to implement AI not only to promote their products and services to consumers, but also to influence responsible travel behaviour and achieve other social marketing goals in support of sustainability. As suggested in previous studies, behaviour change interventions could be more effective if tailored to consumer groups based on key factors likely to support the target behaviour to materialise [15]. Given that consumers seem to derive their confidence and trust in intelligent agents from perceived consequences of using (and interacting with) the technologies [11], it is important that behaviour interventions targeting consumers' reliance on AI (i.e., whose target behaviour is consumers following recommendations from AI) pay particular attention to the perceived positive and negative impacts of AI adoption. This calls for consumer segmentation and profiling based on detailed understanding of shared attitudes toward AI.

Studies have shown the importance of targeting lead users for diffusion of innovative products, services, and technologies $[16,17]$. In the environment where consumers are overwhelmed with the speed of technological innovation and the resulting technological solutions/products, behavioural responses associated with new technologies are ever more complex and harder to predict [18]. As a result, companies are facing new challenges to segment consumers into meaningful groups in order to predict technology adoption. To that end, attitudinal segmentation approach has been applied to identify homogenous groups within a heterogenous market with shared values toward adoption of self-service technology [19, 20], technology-enabled service delivery [21], and mobile marketing [18]. In these studies, attitudes toward technology were considered one of key determinants to classify consumers into adopter vs. nonadopter segments, or into Roger's five user categories in innovation diffusion [22]: innovator-laggard segments.

Since technology adoption decisions are linked to innovativeness [17], consumer segments have been profiled in terms of their personal characteristics as they relate to the levels of personal innovativeness in the domain of information technology. For example, age and gender have been associated with personal innovativeness: younger consumers tend to be more innovative [23] and men tend to adopt new technologies earlier than women [23, 24]. Several studies also linked income and education levels to innovative predispositions: consumers with higher income and education tend to be more innovative and likely to adopt new products faster than their counterparts $[24,25$, 26]. Therefore, identifying significant differences in personal characteristics between distinct consumer segments with differing views of AI impacts on society will assist in 
uncovering the basic attitudinal factors that explain AI adoption for behavioural interventions supporting sustainable tourism.

\section{Method}

In order to achieve the aforementioned research objectives, an online questionnaire was developed to capture travellers' perception of the impacts of intelligent systems (including AI and robotics) in society. A list of items representing benefits and risks of AI implementation was developed from a comprehensive industry research on consumer perception of AI tested in the US, Canada, the United Kingdom (UK), China, and Brazil [3]. The list consists of 13 items representing benefits and 13 items representing risks of AI. These items were presented in a 5-point Likert-type scale, anchored from 1 (strongly disagree) to 5 (strongly agree). To assess the predictive validity of the resulting consumer segments in terms of behavioural intention associated with reliance on AI, respondents were asked to state how likely they are to follow recommendations from AI systems implemented in a smart hotel room while traveling. This question was presented after a scenario asking them to imagine staying in a hotel room equipped with an intelligent virtual/robotic assistant (powered by AI) that gives feedback on resource consumption (i.e., promotion of resource-efficient behaviour to use water/energy more responsibly). The questionnaire also includes demographic characteristics and prior use of AI tools to facilitate consumer profiling.

The questionnaire was distributed online to a survey panel in June 2018 targeting residents of the UK and the US who have travelled domestically or internationally and have stayed in a hotel or other commercial accommodation within the past six months. A total of 621 responses were collected: 313 from the UK and 308 from the US. There is a relatively balanced distribution in terms of gender (51\% male). Respondents are relatively older (59\% of respondents are 55 years and over), mostly college-educated ( $42 \%$ have at least a Bachelor's Degree), and about $55 \%$ stated having annual income less than US\$60,000. In an attempt to explore consumer characteristics in association with their perception of impacts of AI, exploratory factor analysis (principal component analysis/PCA), cluster analysis, discriminant function analysis, and one-way analysis of variance (ANOVA) were implemented to analyse the data.

\section{Result and Discussion}

\subsection{Identifying Perceived Impacts of AI}

To identify important dimensions underlying consumers' perceived impacts of AI, PCA was conducted on the list of items representing perceived benefits and risks of intelligent systems. Three factors emerged from the analysis, accounting for about $70 \%$ of the total variance in the data (see Table 1). The Kaiser-Mayer-Olkin test yielded a score of $0.941(p<0.001)$, indicating sampling adequacy for each of the variables in the model and for the complete model. The first dimension, labelled as Beneficial AI, explains travellers' perception about the benefits of intelligent systems for individuals and society, which include general positive impacts of AI on the economy and the environment as well as the practical benefits from time savings and conveniences. The second, labelled as Destructive AI, explains how AI was expected to cause destruction on infrastructure, endanger political stability, and cause accidents involving humans. 
The last dimension, labelled as Risky AI, reflects consumers' concerns that AI will facilitate crimes, invasion of privacy, and job losses. Two items, associated with AI lessening people's skills and causing humans to be lazy and less industrious, were dropped from the analysis due to high cross-loadings on the two risk dimensions.

Table 1. Principal Components of Perceived Impacts of AI

\begin{tabular}{|c|c|c|c|c|}
\hline Perceived Impacts of AI & $\begin{array}{c}\text { Factor } \\
\text { Loading }\end{array}$ & $\begin{array}{l}\text { Eigen- } \\
\text { value }\end{array}$ & Cum. & $\begin{array}{c}\text { Cronbach's } \\
\alpha\end{array}$ \\
\hline Factor 1: Beneficial AI & & 8.522 & 35.510 & 0.957 \\
\hline $\begin{array}{l}\text {...easier decision-making for purchases of } \\
\text { products or services. }\end{array}$ & 0.858 & & & \\
\hline $\begin{array}{l}\text {...products and services that provide greater } \\
\text { ease and convenience. }\end{array}$ & 0.851 & & & \\
\hline $\begin{array}{l}\text {...improvements to human health and/or } \\
\text { longevity. }\end{array}$ & 0.832 & & & \\
\hline $\begin{array}{l}\text {...time savings, freeing up humans to pursue } \\
\text { other activities or leisure. }\end{array}$ & 0.831 & & & \\
\hline ...better skills at solving complex problems. & 0.831 & & & \\
\hline ...a positive impact on our economy. & 0.826 & & & \\
\hline ...better use of energy and natural resources. & 0.806 & & & \\
\hline ...a positive impact on our environment. & 0.804 & & & \\
\hline $\begin{array}{l}\text {...easier access of relevant news and } \\
\text { information. }\end{array}$ & 0.792 & & & \\
\hline ...greater social equality. & 0.774 & & & \\
\hline $\begin{array}{l}\text {...lower-priced or more affordable products } \\
\text { and services. }\end{array}$ & 0.750 & & & \\
\hline ...companionship. & 0.746 & & & \\
\hline $\begin{array}{l}\text {..completion of tasks that are too hard or } \\
\text { too dangerous for people. }\end{array}$ & 0.728 & & & \\
\hline Factor 2: Destructive AI & & 4.311 & 53.471 & 0.907 \\
\hline ...harmful impacts on our environment. & 0.859 & & & \\
\hline ...transportation problems. & 0.834 & & & \\
\hline ...disruptions to infrastructure. & 0.766 & & & \\
\hline ...ease of going to war. & 0.746 & & & \\
\hline ...accidents involving humans. & 0.740 & & & \\
\hline $\begin{array}{l}\text {...manipulation of humans by intelligent } \\
\text { machines or technologies. }\end{array}$ & 0.676 & & & \\
\hline Factor 3: Risky AI & & 3.871 & 69.599 & 0.900 \\
\hline ...cyber-attacks or computer hacking. & 0.863 & & & \\
\hline ...less security of personal data and privacy. & 0.793 & & & \\
\hline ...criminal use of AI technologies. & 0.788 & & & \\
\hline $\begin{array}{l}\text {...companies/government with more access } \\
\text { to personal data/behaviour. }\end{array}$ & 0.786 & & & \\
\hline ...job losses. & 0.694 & & & \\
\hline
\end{tabular}

\subsection{Segmenting Travel Consumers on Perceived Impacts of AI}

To explore whether travel consumers can be categorised into meaningfully distinct groups based on their perception of the impacts of AI, hierarchical cluster analysis was 
performed on the three dimensions of perceived impacts of AI, using squared Euclidian distance measure and Ward's agglomeration criterion. Initially, 1-, 2-, 3-, and 4-cluster solutions were compared. Finally, the 3 -cluster solution was selected for its cluster distinctiveness and overall interpretability. Based on the mean scores of perceived impacts of AI amongst the three clusters (see Table 2), the groups are named: The Laggards $(n=109)$, The Aficionados $(n=57)$, and The Realists $(n=455)$. The Laggards and The Aficionados appear to be on the opposite ends of the continuum when it comes to perceiving positive and negative impacts of AI; The Laggards highly believe in Destructive AI and Risky AI, while The Aficionados in Beneficial AI. However, The Realists demonstrate awareness in both benefits and risks of AI implementation, with mean scores of Risky AI and Beneficial AI both above neutral.

Table 2. Consumer Segments and Perceived Impacts of AI

\begin{tabular}{lccc} 
& \multicolumn{3}{c}{ Mean (St. Dev.) } \\
\cline { 2 - 4 } Perceived Impacts of AI & The Laggards & The Aficionados & The Realists \\
\hline Beneficial AI & $1.997(0.575)$ & $3.910(0.861)$ & $3.569(0.606)$ \\
Destructive AI & $3.789(0.710)$ & $1.620(0.546)$ & $3.062(0.629)$ \\
Risky AI & $4.389(0.589)$ & $2.217(0.822)$ & $3.836(0.624)$
\end{tabular}

This pattern is further illustrated in Fig. 1, where the three clusters are compared in terms of the individual items representing the benefits (on the right-hand side of the radar) and the risks (on the left-hand side of the radar) of AI. The Laggards (in blue) score higher on the negative items, while The Aficionados (in red) on the positive ones. The Realists (in green) score slightly lower than the highs in the other two clusters (on both ends).

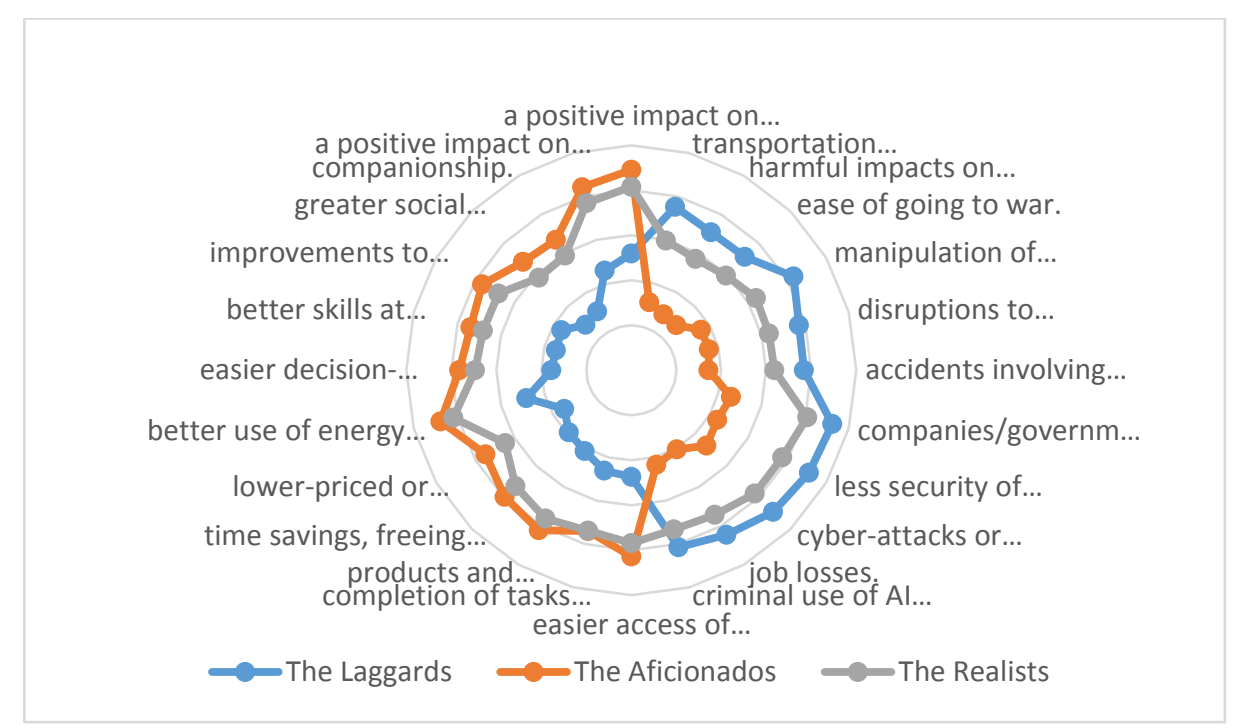

Fig. 1. Consumer Segments and Perceived Benefits and Risks of AI (Mean Scores) 
To identify whether respondents are maximally separated into the three groups and that the variables contribute meaningfully to the classification, discriminant function analysis was performed. The Wilk's Lambda test for the discriminant function yielded 0.261 ( $p<0.001$ ), indicating a good discriminatory ability of the function, and Eigenvalue of 1.975 , with the function accounting for $87.4 \%$ of variance in the dependent variables (i.e., consumer groups). Table 3 presents the tests of equality of group means and structure matrix to identify which variable contributes a significant amount of prediction to help separate the groups. The smaller the Wilk's Lambda, the more important the variable for the discriminant function. In the structure matrix, the coefficients with large absolute values correspond to variables with a greater ability to discriminate between the three groups. The contribution of the three variables are comparable, with Beneficial AI contributing slightly better to discriminate consumers into the three groups (from both Wilk's Lambda and structure matrix). Finally, Table 4 presents classification function coefficients (Fisher's linear discriminant functions), which can be used to predict group membership of travel consumers. Overall, the classification results show a high success rate; $93.1 \%$ of the original grouped cases were correctly classified into the three clusters.

Table 3. Test of Equality of Group Means and Structure Matrix

\begin{tabular}{lcccc} 
Perceived Impacts of AI & Wilk's Lambda & F (2, 618) & Sig. & $\begin{array}{c}\text { Structure } \\
\text { Matrix }\end{array}$ \\
\hline Beneficial AI & 0.505 & 302.514 & $<0.001$ & -0.643 \\
Destructive AI & 0.587 & 217.005 & $<0.001$ & 0.568 \\
Risky AI & 0.582 & 221.808 & $<0.001$ & 0.543
\end{tabular}

Table 4. Classification Function Coefficients

\begin{tabular}{lrrr} 
Perceived Impacts of AI & The Laggards & The Aficionados & \multicolumn{1}{c}{ The Realists } \\
\hline Beneficial AI & 3.611 & 9.321 & 7.877 \\
Destructive AI & 6.422 & 2.063 & 4.693 \\
Risky AI & 8.362 & 3.789 & 7.088 \\
(Constant) & -35.221 & -25.192 & -35.932
\end{tabular}

\subsection{Profiling Consumer Segments}

To further uncover the profiles of the consumer clusters, Pearson Chi-Square tests were performed to detect significant differences in terms of demographic characteristics of the cluster members. Table 5 shows how the clusters are significantly different across gender, age, and country of residence. Characteristically, The Laggards are dominated by male $(62 \%)$ and older $(78 \%$ are 55 or older) travellers, while US residents are dominant in The Aficionados (70\%). No significant differences were found in terms of education and household income levels, although it is worth noting that while both The Aficionados and The Realists have a balanced distribution between respondents with a Bachelor's Degree (or higher) and without, $60 \%$ of The Laggards have no higher degree (lower than Bachelor's). Furthermore, about $62 \%$ of The Laggards have less than US\$60,000 in annual household income, while $61 \%$ of The Aficionados have US $\$ 60,000$ or higher. The percentages are balanced for The Realists. 
Table 5. Demographic Profiles

\begin{tabular}{cccccc} 
Profiles & The Laggards & The Aficionados & The Realists & $\chi^{2}$ & Sig. \\
\hline $\begin{array}{c}\text { Gender } \\
\text { Male }\end{array}$ & $62 \%$ & $54 \%$ & $48 \%$ & & \\
Female & $38 \%$ & $46 \%$ & $52 \%$ & & \\
Age & & & & 26.020 & 0.004 \\
$18-24$ & $1 \%$ & $2 \%$ & $4 \%$ & & \\
$25-34$ & $2 \%$ & $2 \%$ & $9 \%$ & & \\
$35-44$ & $6 \%$ & $19 \%$ & $12 \%$ & & \\
$45-54$ & $19 \%$ & $30 \%$ & $18 \%$ & & \\
$55-64$ & $44 \%$ & $28 \%$ & $33 \%$ & & \\
$65+$ & $29 \%$ & $19 \%$ & $25 \%$ & & \\
Residence & & & & 10.660 & 0.005 \\
UK & $53 \%$ & $30 \%$ & $52 \%$ & & \\
US & $47 \%$ & $70 \%$ & $48 \%$ & &
\end{tabular}

Further, in order to confirm previous findings linking prior use of AI and perception, the tests were also performed on the use of AI systems in the past six months. As seen in Table 6, there are statistically significant differences in prior use of virtual assistant (such as Siri), voice search, real-time automatic translation, and other digital personal assistant(s) among the three groups. Unsurprisingly, the proportions of those who have used the tools are highest in The Aficionados and lowest in The Laggards. Notably, nearly half of The Aficionados have used voice search tools in the past six months. About a third of The Realists have used voice search and virtual assistants.

Table 6. Use of AI Tools in the Past Six Months

\begin{tabular}{lccccc} 
AI Tools & $\begin{array}{c}\text { The } \\
\text { Laggards }\end{array}$ & $\begin{array}{c}\text { The } \\
\text { Aficionados }\end{array}$ & $\begin{array}{c}\text { The } \\
\text { Realists }\end{array}$ & $\chi^{2}$ & Sig. \\
\hline $\begin{array}{l}\text { Virtual assistant (e.g. Siri) } \\
\quad \text { No }\end{array}$ & $82 \%$ & $63 \%$ & $70 \%$ & 7.783 & 0.020 \\
$\quad \begin{array}{l}\text { Yes } \\
\text { Voice search }\end{array}$ & $18 \%$ & $37 \%$ & $30 \%$ & & \\
$\quad$ No & $82 \%$ & $51 \%$ & $67 \%$ & & \\
$\quad \begin{array}{l}\text { Yes } \\
\text { Real-time automatic }\end{array}$ & $18 \%$ & $49 \%$ & $33 \%$ & & \\
translation & & & & 10.034 & 0.007 \\
$\quad$ No & $93 \%$ & $79 \%$ & $80 \%$ & & \\
$\quad \begin{array}{l}\text { Yes } \\
\text { Other digital personal }\end{array}$ & $7 \%$ & $21 \%$ & $20 \%$ & & \\
assistant(s) & & & & 11.493 & 0.003 \\
$\quad$ No & & & & \\
$\quad$ Yes & $95 \%$ & $79 \%$ & $84 \%$ & & \\
\end{tabular}

Based on the number of members in each cluster as well as the distinctiveness of their demographic characteristics and use behaviour, it can be suggested that The Realists represent the mainstream consumers when it comes to perception of AI impacts. 


\subsection{Consumer Segments and AI-related Behavioural Intention}

To assess whether cluster memberships can explain consumer behaviour associated with reliance on AI, one-way ANOVA was performed on intention to follow recommendation from AI-powered virtual/robotic assistant in a smart hotel room designed to provide feedback and advice on resource consumption (i.e., energy and water). As shown in Table 7 and Fig. 2, there are significant differences in the mean intention to follow recommendation from AI system between the different clusters $(F$ $(2,618)=146.346, p<0.001)$. From the results of the Tukey post hoc test, it was identified that compared to The Laggards (1.972 $\pm 1.023, p<0.001)$, intention to follow recommendation from AI was statistically significantly higher for The Aficionados $(4.192 \pm 0.972, p<0.001)$ and The Realists $(3.670 \pm 0.994, p<0.001)$. Also, there is a significant difference between The Aficionados (higher) and The Realists $(p=0.001)$.

Table 7. Consumer Segments and Intention to Follow Recommendation from AI

\begin{tabular}{lrrrrr} 
Source & Sum of Squares & Df & $\begin{array}{c}\text { Mean } \\
\text { Square }\end{array}$ & \multicolumn{1}{c}{ F } & Sig. \\
\hline Between Groups & 290.960 & 2 & 145.480 & 146.346 & $<0.001$ \\
Within Groups & 614.344 & 618 & 0.994 & & \\
Total & 905.304 & 620 & & &
\end{tabular}

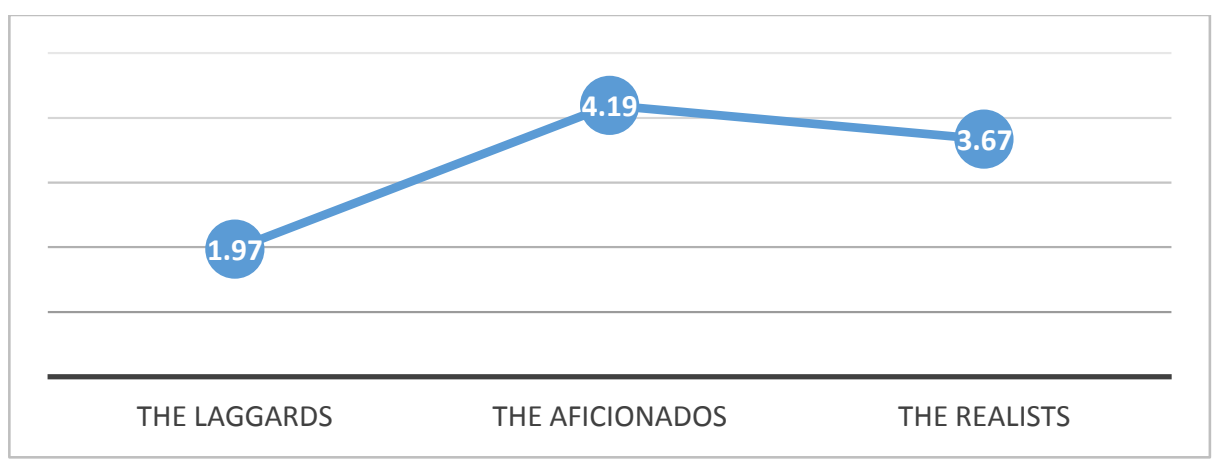

Fig. 2. Consumer Segments and Intention to Follow Recommendation from AI

These results show that the consumer groups generated based on perception of AI impacts in general can be useful in predicting behaviour with regards to AI adoption in the travel contexts. That is, consumers who expect AI to bring positive impacts to society, economy, the environment, and people in general (i.e., not specific to travel, tourism and hospitality settings) will develop higher intention to rely on AI while traveling. That is, global perceptions of AI will manifest in specific (local) behaviour.

\section{Conclusion and Recommendation}

This research explores consumers' perceptions with regards to the impacts of AI in society and segment consumers based on these perceptions. The ultimate goal was to assess whether differing perspectives of AI explain consumer behavioural responses to 
AI systems recommending responsible travel behaviour to support sustainability. Three underlying factors of perceived AI impacts emerged: Beneficial AI (optimistic), Destructive AI and Risky AI (pessimistic). The two pessimistic views of AI appear to differ in terms of AI as the source of harm, Destructive AI represents direct outcomes of AI implementation (e.g., AI damages society), while Risky AI represents indirect outcomes (e.g., AI facilitates other entities such as criminals to harm society). These further confirm and explain the two opposing views of AI impacts in society, as suggested in previous research [3, 12].

These factors successfully classified consumers into three distinct segments: The Laggards (who perceive high level of risks and low level of benefits of AI), The Aficionados (who perceive high level of benefits and low level of risks of AI), and The Realists (who are aware of both likely benefits and risks of AI). The majority of consumers belong to The Realists, with a small number belonging to The Aficionados and a slightly larger number to The Laggards. The Laggards are rather distinctive in their personal characteristics compared to the other two segments; they are dominated by male and older travellers, likely with lower levels of income and education, and most have not used any AI tools as of recent. Some of these findings are consistent with previous studies linking personal characteristics to level of personal innovativeness in the domain of information technology [23, 24].

Tested in terms of intention to follow recommendations from AI, the three groups demonstrated different behavioural responses. The Laggards are the least likely to follow recommendations from AI, while The Aficionados are the most likely to do so. The Realists exhibit significantly higher likelihood to adopt recommendations from AI when compared to The Laggards, but still lower than the Aficionados do. This implies that the use of AI for positive behaviour change will likely be effective in the majority of travel consumers. Behaviour change intervention efforts will be ineffective only in a small proportion of travel consumers who hold negative attitudes toward AI. Therefore, it is highly suggested that travel companies and tourism destinations integrate proenvironmental and prosocial campaign efforts into the implementation of $\mathrm{AI}$ in order to balance the economic gains from $\mathrm{AI}$ adoption with sustainable tourism goals.

While contributing to explicating the roles of AI in positive behaviour change intervention, thus opening a pathway for policy and strategic implementation supporting sustainable tourism, this research has several limitations that should be accommodated in future research. First, albeit using proenvironmental behaviour as the intervention target in the research context, this research did not consider factors associated with responsible behaviour such as environmental concerns in the segmentation procedure. Future research should combine proenvironmental values and attitudes toward AI to classify consumers into more detailed segments in order to better predict the effectiveness of behaviour change interventions supporting sustainable tourism. Second, this research only tested the association between the segments and intention to follow AI recommendations, but did not test any causal relationships between the variables. Future studies should develop a predictive attitudinal and behavioural model to test the predictive validity of perceived impacts of AI on travellers' behaviour in various contexts. Lastly, future studies should experiment 
behaviour change interventions with actual consumers to empirically test the effectiveness of such interventions with in different consumer groups.

\section{References}

1. An M (2017) Artificial Intelligence Is Here - People Just Don't Realize It. https://research.hubspot.com/artificial-intelligence-is-here, last accessed: 2018/08/10

2. Krogue K, Larsen G, Parry B (2017) The State of Artificial Intelligence, 2017: Public Perceptions of the Most Disruptive Technology (UK Edition). https://uk.insidesales.com/wp-content/uploads/2017/03/State_of_AI_UK.pdf, last accessed: 2018/08/10

3. Weber Shandwick (2016) AI-Ready or not: Artificial Intelligence Here We Come! What Consumers Think \& What Marketers Need to Know. https://www.webershandwick.com/uploads/news/files/AI-Ready-or-Not-report-Oct12FINAL.pdf, last accessed: 2018/08/10

4. PwC (2017) Sizing the Prize: What's the Real Value of AI for Your Business and How can You Capitalise? https://www.pwc.com/gx/en/issues/analytics/assets/pwc-ai-analysissizing-the-prize-report.pdf, last accessed: 2018/08/10

5. Economist (2016) Artificial Intelligence in the Real World. https://www.eiuperspectives.economist.com/sites/default/files/Artificial_intelligence_in _the_real_world_1.pdf, last accessed: 2018/08/10

6. Russell S, Dewey D, Tegmark M (2015) Research Priorities for Robust and Beneficial Artificial Intelligence. AI Magazine, 36(4), 105-114.

7. Lee JD, See, KA (2004) Trust in automation: designing for appropriate reliance. Human Factors, 46(1), 40-80.

8. Tromp N, Hekkert P, Verbeek P-P (2011) Design for socially responsible behavior: A classification of influence based on intended user experience. Design Issues, 27(3), 3-19.

9. Tussyadiah IP (2017) Technology and Behavioral Design in Tourism. In: Fesenmaier DR, Xiang Z (eds.), Design Science in Tourism. Springer International Publishing, Switzerland, pp. 173-191. doi: 10.1007/978-3-319-42773-7_12

10. Gretzel U (2011) Intelligent System in Tourism: A Social Science Perspective. Annals of Tourism Research, 38(3), 757-779.

11. Tussyadiah IP, Wang D. (2016) Tourists' Attitudes toward Proactive Smartphone Systems. Journal of Travel Research, 55(4), 493-508. doi: 10.1177/0047287514563168

12. Fast E, Horvitz E (2017) Long-Term Trends in the Public Perception of Artificial Intelligence. In: Proceedings of the Thirty-First AAAI Conference on Artificial Intelligence. International Joint Conferences on Artificial Intelligence, Inc.: Menlo Park, CA, pp. 963-969.

13. Brougham D, Haar J (2018) Smart Technology, Artificial Intelligence, Robotics, and Algorithms (STARA): Employees' perceptions of our future workplace. Journal of Management \& Organization, 24(2), 239-257. doi:10.1017/jmo.2016.55

14. Tussyadiah IP, Zach FJ, Wang J (2017) Attitude toward Autonomous On-Demand Mobility: The Case of Self-Driving Taxi. In: Schegg R, Stangl B (eds) Information and Communication Technologies in Tourism 2017, Springer International Publishing, Switzerland, pp. 755-766. doi: 10.1007/978-3-319-51168-9_54

15. Hardcastle SJ, Hagger MS (2015) Psychographic Profiling for Effective Health Behavior Change Interventions. Frontiers in Psychology, 6:1988. doi:10.3389/fpsyg.2015.01988.

16. Morrison PD, Roberts JH, Midgley DF (2004) The nature of lead users and measurement of leading edge status. Research Policy, 33(2), 351-362.

17. Schreier M, Oberhauser S, Prügl R (2007) Lead users and the adoption and diffusion of new products: Insights from two extreme sports communities. Marketing Letters, 18(1-2), 15-30. 
18. De Marez L, Vyncke P, Berte K, Schuurman D, De Moor K (2007) Adopter Segments, Adoption Determinants and Mobile Marketing. Journal of Targeting, Measurement and Analysis for Marketing, 16(1), 78-95. doi: 10.1057/palgrave.jt.5750057

19. Bobbitt LM, Dabholkar PA (2001) Integrating Attitudinal Theories to Understand and Predict Use of Technology-Based Self-Service: The Internet as an Illustration. International Journal of Service Industry Management, 12(5), 423-450.

20. Dabholkar PA, Bagozzi RP (2002) An Attitudinal Model of Technology-Based SelfService: Moderating Effects of Consumer Traits and Situational Factors. Journal of the Academy of Marketing Science, 30: 184.

21. Walker RH, Craig-Lees M, Hecker R, Francis H (2002) Technology-Enabled Service Delivery: An Investigation of Reasons Affecting Customer Adoption and Rejection. International Journal of Service Industry Management, 13(1), 91-106.

22. Rogers EM (2003) The Diffusion of Innovation (5th Ed). Free Press: New York.

23. Steenkamp J-BEM, Burgess SM (2002) Optimum stimulation level and exploratory consumer behavior in an emerging consumer market. International Journal of Research in Marketing, 19(2), 131-150.

24. Tussyadiah IP (2016) The Influence of Innovativeness on On-Site Smartphone Use among American Travelers: Implications for Context-based Push Marketing. Journal of Travel \& Tourism Marketing, 33(6), 806-823. doi: 10.1080/10548408.2015.1068263

25. Im S, Bayus BL, Mason CH (2003) An Empirical Study of Innate Consumer Innovativeness, Personal Characteristics, and New-Product Adoption Behavior. Journal of the Academy of Marketing Science, 31(1), 61-73.

26. Tellis GJ, Yin E, Bell S (2004) Global Consumer Innovativeness: Cross-Country Differences and Demographic Commonalities. Journal of International Marketing: June 2009, 17(2), 1-22.

\section{Acknowledgements}

This work was supported by the University of Surrey's Faculty of Arts and Social Sciences (Pump Priming Fund 2017/2018). 